\title{
Exorbitant Responsibility: Geographies of Climate Justice
}

Nigel Clark and Yasmin Gunaratnam

Forthcoming in Climate Futures: Re-imagining Global Climate Justice_eds._Kum-Kum

Bhavnani, John Foran, Priya A. Kurian, Debashish Munshi_(University of California Press)

\section{Connecting with Climate Change}

'If climate change makes our country uninhabitable, we will march with our wet feet into your living rooms'. With this impassioned intervention at a 1995 Berlin climate change forum, Bangladeshi representative Atiq Rahman vented his frustration with the stalling of international climate negotiations (cited in Roberts and Parks, 2007: 2). As burgeoning studies around the question of climate migration have since made clear, there is no simple, linear relation between vulnerability to extreme weather and long distance mobilization. But that most likely wasn't Rahman's point.

One of the great challenges of climate change, as Sheila Jasanoff puts it, is that the scientific evidence upon which issue formation depends `cuts against the grain of ordinary human experience' (2010: 237). Both its causes and effects seem too widely distributed in space and time for us to grasp palpably, immediately, personally. What Rahman seems to be doing, in this regard, is trying to shift the issue of climate change away from planetary modelling and abstraction so as to remind us that those on the sharp edge of climate change are flesh and blood people whose potential suffering ought to be 'in our face’. 
This is the kind of work that critical human geographers take to be vital and urgent. As we will see, human geographers specialise in tracing the complex patterns of interconnectivity that implicate the lives of people 'here' with others near or far. Though we go about this systematically - gathering as much evidence as we can - most of us are driven to do this because we care about the unequal and unjust ways that life chances are distributed in the contemporary world. But this task soon gets complicated. Can we assume that the tracking and calculating unfair exchanges is an effective way to make people care more about distant others? Is a calculus of trans-global gains and losses really the best means of encouraging empathy and compassion for vulnerable others?

Increasingly, human geographers are concerned not only with the social processes that render global 'playing fields' uneven, but with the many nonhuman phenomena that help compose these bumpy, irregular realities. But things get even trickier when we factor in the workings of the earth itself. Global climate is an immensely complex system, with more connections, nodes and feedbacks than almost any known system. In such a world, no single climatic event can be unambiguously attributed to anthropogenic influences, let alone pinned to the actions of a group or category of people. And even if we could somehow level the global socio-economic playing field, this is a planet whose ordinary, ongoing instability would still make social life - from time to time - immensely challenging.

If it's not easy to unequivocally map out chains of causality for climate change, so too is it difficult to predict how different collectivities will react to shifting or extreme climatic conditions. For example, we have indeed witnessed groups of South Asians, many of whom were of Bangladeshi origin, marching wet-footed through the streets and living rooms of Lancashire, Cumbria and southern Scotland. However, they came not as displaced people, but as emergency relief squads responding to flooding during 
December 2015's Storm Desmond. Faith-based organisations in the north of England experienced in responding to extreme events overseas - mobilised quickly to provide food, supplies and clean-up assistance to flood-struck communities closer to home (York, 2015).

It is unlikely that these people came to help because they felt in any way liable. They may not have felt, in advance of the floods, particularly connected to the afflicted communities, though in the act of assuming responsibility they certainly made new connections. But should we view such a gesture - a reaching out by strangers to those in need - as exceptional? Or is there, in its very generosity and compassion, something rather ordinary about such a response? What if a 'geographical' imagining of justice and responsibility in a time of climate change, we want to ask, were to set out from such overtures? Where might we end up? On what kind of journey might it take us?

\section{Mapping Climate Injustice}

In earlier days of concern over climate change, climatologists seemed to work under the assumption that providing relevant data would be enough to spur decision-makers to deal with the problem. When evidence of present and predicted climate change - even potentially catastrophic shifts - proved insufficient to spark the necessary policy responses, it became apparent that there was more at stake than `a deficit of understanding' (T Clark, 2015: 160). Attracted to the irrupting debate, critical social thinkers set out to show how existing patterns of energy use were bound up with powerful vested interests. They also assembled evidence that demonstrated how vulnerability to climate change mapped uncannily onto disadvantages associated with the vast socio-structural inequalities rifting the global economy. Not only were already underprivileged regions disproportionately susceptible to changing climate - especially with regard to projected agricultural outputs - research suggested they would also find 
themselves under-resourced when it came to adapting to changing conditions and further disadvantaged in their efforts to maintain a strong presence in global climate negotiations (Newell, 2005; Clark et al, 2013).

There is a deep-seated moral-political dimension to this sort of articulation of global climate injustice. Like Rahman's outcry, such interventions not only seek to expose the inequity structured into global social orders, but attempt to bring climate change controversies back to the scale and experiences of daily life. In this way, critical social researchers hope to add a vital charge of care and compassion to the too often selfserving and conditional world of international climate negotiation - to help jolt it out of its costly stalemates, delays and deferrals (Roberts and Parks 2007, 221-226).

It is here that critical human geographers like to feel that our spatial imaginations and skills shine, for we see ourselves as geared up to map out the routes, vectors and networks through which everyday lives ‘here’ connect with lives elsewhere and wellequipped to show how these pathways serve as the very medium through which unfairness is perpetuated. In this way, geographers reveal how it is that those of us living in more privileged places benefit from unequal spatial relations - in quite mundane ways. Whether it is by using oil extracted from distant lands, consuming cheap calories others have grown, or adding disproportionately to greenhouse gas emissions, our stories indicate, those of us enjoying relatively high standards of living are implicated in the underprivilege, expropriation and suffering that is happening 'elsewhere' - beyond our usual sightlines.

The assumption underlying such accounts is that by attending closely to the ways that our lives are entangled with other lives, we will feel obliged to take greater responsibility for our daily deeds and for the very organization of our interchanges with others. But lately, geographers have begun to ask themselves some tough questions about this 
supposed passage from recognizing causal links between 'our' actions and 'their' predicaments to the emergence of more caring and compassionate ways of relating. For just as overcoming 'deficits' of scientific understanding about climate change does not automatically produce effective policy, neither does it appear that exposing deficits of political understanding or of moral sensibility leads straightforwardly to appropriately virtuous dispositions or measures.

As Clive Barnett and David Land put it: ‘the mere fact of being bound into relationships with distant others does not actually provide any compelling reason that could account for or motivate relationships of care, concern, or obligation' (2007: 1069). Climate change is a good example. Given that anyone's personal contribution to greenhouse gas build-up will rebound through the unfathomably complex interconnectivities of the entire earth system - this would seem a rather convoluted way to come to care passionately about actual, flesh and blood people. For sure, having a reasonable sense of the mutual implication between places near and far does no harm, and indeed has become a significant part of global climate negotiation. But some critical spatial thinkers are asking whether there might not be better ways of understanding - and encouraging the emergence of responsible, caring or compassionate dispositions towards 'others'.

For a start, whatever news media tell us, kindness, empathy and generosity are not necessarily in short supply. As ethical thinkers point out, while they may not get the credit they deserve in competitive economies or bureaucratic systems, such virtues are the ordinary and ubiquitous 'load-bearing structures of society’ (Vaughan, 2002: 98). Mostly murmuring away in innumerable uncelebrated acts, caring and generous overtures often flare into visibility in times of crisis, such as during Storm Desmond, Hurricane Katrina or any number of well-documented calamities (Clark, 2011: Ch 3). While help from those in the vicinity may be most urgently needed, there is plentiful evidence - 
embodied in donations, volunteering, professional organizations and social movements that caring gestures reach far across the planet. Moreover, such outpourings of empathy, support and assistance in the face of extremity suggest that compassion does not wait upon the revealing of causal connections or culpability in order to go forth.

What happens, then, when climate change arrives not in calamitous, rapid onset events, but in the ‘slower violence' of chronic environmental change or ever more routinized conditions of extremity? There has recently been growing attention to the way urban populations are responding to climate stress, especially in cities where infrastructure cannot be relied upon to cope with escalating pressure. In Mumbai, monsoonal flooding is now considered 'normal', while parts of Jakarta were inundated five times in 2015. In these `ordinary cities’ of the Global South, numerous forms of improvised response to enhanced climatic variability can be observed, ranging from architectural innovations including green shading to reduce heat stress and the elevation of furniture or housing (Banks et al 2011) through to new social media platforms such as Jakarta's real-time flood mapping application that enables citizens to collaborate in the management of flooded cityscapes (Holderness and Turpin, 2016).

Here too, on the frontline of global climate change, the question of care, compassion and generosity as everyday social 'load-bearing structures’ calls for special consideration. In cities of the South associations of neighbours, relatives and friends provide vital support for weathering extreme events - in the form of provisions, temporary shelter, information and financial assistance (Roy and Hulme 2013; Jabeen et al, 2010). While most researchers stress the gradual, mutual building of trust in such informal networks, some have also noted how spontaneous offerings of assistance often precede - or exceed - any reciprocal arrangement. Jonathan Shapiro Anjaria (2006), for example, provides a moving account of responses to Mumbai's exceptionally severe flooding of 2005 in which some of the city's poorest and most marginalised people effectively self-organised 
to help stranded strangers.

Just as we should not presume that those with the relatively few resources will be slow to make generous offerings, neither should we assume such openings are restricted to the local scale. When super-typhoon Haiyan (Yolanda) struck the Philippines in 2013, there were once again many ground-level `stories of hope, courage, creativity, and empowerment' as low-income, under-resourced people came together to endure catastrophic conditions (Valerio, 2014: 156). A great many of those who rallied to raise funds for relief and reconstruction were transnational workers. As Cleovi Mosuela and Denise Matias observe: ‘cross-border migrants ... constitute an international network of Filipinos who are instrumental not only in keeping the Philippine economy afloat but also in constituting a network that may serve as a response to major environmental disasters in the Philippines' (2014: 8).

Rather than supposing that we need to begin with carefully computed geographies of who owes what to whom, then, a case might be made for setting out from the mundane reality of people reaching out to each other in times of stress and need - and working up from there. If justice is going to work, to push through the barriers that are endlessly thrown up in its path, we must truly, deeply desire that others be relieved of their suffering and deprivation. But while justice may need care and compassion, these virtues themselves tend not to await a calculus of costs, debts, liabilities. They seem most often to emerge from actual encounters with others (which does mean that they have to be direct or unmediated). As we suggest in the final section, a consideration of these at once ordinary and extraordinary acts of care and compassion might help us come to terms with living on an inherently changeable planet. Though if we wish to respond both fairly and effectively to climate change, this by no means absolves us from doing the most exacting calculations. 


\section{Exorbitant Responsibility}

To pursue climate justice is to ask what kind of social world we inhabit - to probe its ruptures, imbalances, clashes. While we have been suggesting that tallying gains and losses might not be the only or best starting point for responding care-fully to climate change, it is also vital to recognize the acknowledging widespread capacities for self-help or self-organization in a profoundly uneven world runs the risk of abetting those who would leave the poor, marginalized and vulnerable to their own devices in times of extremity. More disturbingly, it could play into recent policy moves to encourage the selective uptake of most flexible and resourceful disadvantaged people on the frontline of climate change into global economies - in a kind of 'positive' climate migration that once leaves the most vulnerable behind and takes away those who might have been best able to care for them (Bettini, 2014).

In short, if we are to care more - and if we wish to help others in their own caring practices - then we also need to keep a close eye on the deeply and often cruelly imbalanced forms of calculation that are already at play in the world. And this is but a part of a more general lesson, that if genuine offers of assistance are to be truly effective - however much they precede or break out economies where values are known in advance - it is necessary to do our homework so as to intervene as knowledgeably and judiciously as we can.

As philosopher Jacques Derrida asserts, 'one can't make a responsible decision ...without knowing what one is doing, for what reasons, in view of what and under what conditions' (1995: 24). This means that whenever we make a gift or add our weight to a political conflict, we should also accept that our offerings are quite likely to fall short or miss the mark. To recognise, therefore, that overtures of care or struggles for justice are 
inevitably learning processes in which we find ourselves interrogated, provoked, inspired by the singularity and specific needs of those to whom we attend (Gunaratnam 2013: 47$50)$.

In the case of climate change, such attempts to figure out 'what we are doing' not also mean that we ask what kind of social world we live in, but what kind of planet we inhabit. Over the last fifty years, western science has offered ever more evidence of the inherent dynamism of the earth - conveyed most dramatically in theories of abrupt climate and the Anthropocene thesis. As geoscientists insist: 'detailed paleo-records show that the Earth is never static... variability abounds at nearly all spatial and temporal scales' (Steffen et al, 2004: 295). For many peoples whose cultural memories and earth stories cover long periods, however, such scientific revelations are unlikely to come as a surprise. Here, ecological and geophysical knowledge is often bound up with practices, values and ways of relating that are deeply oriented to the varying demands of a profoundly changeable world.

In this sense, a crucial aspect of pursuing and enacting climate justice would be, acknowledging, learning from, 'doing justice' to, the hard-won achievements of living with earthly variability - as it is engrained in many different kinds of cultures. For all of us, in our own ways, are living beings whose very existence bears witness to the ability of a long line of ancestors to endure whatever the earth has thrown at them over the long march of human emergence (Gunaratnam and Clark, 2013).

Such an approach opens up possibilities of thinking about justice in ways that hinge not only on measurable gains and losses but on gifts or inheritances that are resoundingly incalculable. We dwell in landscapes whose rough edges have been smoothed by past inhabitants, we inherit material cultures, we are living beings whose bodily capacities come to us through the chains of bodies who precede us. And in this sense we are all 
recipients of 'the gift of possibility of a common world' (Diprose, 2002: 141), every one us of owing a vast, immeasurable and irrecompensable debt to all those predecessors who have made our lives possible (Clark, 2010).

But such gifts come down to us deeply inscribed with inequality, the offering of some properly acknowledged while the graft and sacrifice of others is overlooked or undervalued or just plain appropriated (Diprose, 2002: 9). So once again we find ourselves drawn into a world of relations that exceed calculation, only to find ourselves obliged to do a searching and exacting accounting. For even if we are - every one of us - are in debt from the very beginning, some of us are more in debt than others. Or in the words of philosopher Alphonso Lingis: 'To be responsible is always to have to answer for a situation that was in place before I came on the scene' (1998: xx).

What might it mean, then, to confront climate change in terms of a responsibility not only for what I have done - or whatever actions can be pinned on me - but for what or who I am? While not directly related to climate, Peter van Wyck's (2010) account of the Dene people of Canada's Great Bear Lake region seems to offer an example of such a responsibility. The Dene's own storying of the land, recounts van Wyck in a phrase borrowed from Walter Benjamin, moves 'in rhythms comparable to those of the change that has come over the earth's surface in the course of thousands of centuries' (2010: 178). The tribe who had an ancient intuition that something dangerous lay beneath their soil, were inadvertently drawn into the nuclear age when uranium mined by from their tribal lands was used in the atomic bombs detonated over Hiroshima and Nagasaki. In spite of the Dene's ignorance of the of the wartime use of 'their' uranium, the tribe eventually elected to send a delegation to Japan to apologise for their implication in the first aggressive nuclear detonation (2010: 45).

We call this ex-orbitant responsibility not only because it breaks out of the closed circuit 
of calculable exchange, but also because it responds to an earth that no longer seems to spin in a predictable orbit -a planet whose very multiplicity and changeability breaks with earlier ideas of a unified 'whole earth' (Clark, 2016). With its demands to attend both to the deep rumblings of a dynamic earth and to the complex temporalities of inheritance cultural, corporeal, ecological - it seems to us, the exploring or tracing out of exorbitant responsibility invites geographers to give it their very best.

Exorbitant responsibility is endlessly demanding. It calls for constant attentiveness to the appeals of others and to the inevitable inadequacies of all acts of assistance. It requires calculations of which biologist-turned-climate change commentator Tim Flannery has observed: 'Never in the history of humanity has there been a cost-benefit analysis that demands greater scrutiny' (2005: 170). It takes off from a sense of unrepayable indebtedness that stretches back into through an untraceable lineage of bodies into turbulent earth history.

But in the process of reaching into the receding depths of bodies, cultures, past climates and previous phases of the earth system, exorbitant responsibility also offers drama, enchantment, inspiration. It dreams of opening the cold hard world of climate negotiation into an earth/human adventure story of unfathomable intrigue. Excessive forms of climate justice and care, we have been suggesting, set out from a commonplace, everyday reluctance to see the suffering of others go unattended. But for many peoples, in many places, that very sense of having something to offer others is quite mundanely linked to offerings of communities past and present, of ancestors both human and more than human, of a earth enlivened by many lifeforms. In other words, it arises out of `a bond between my present and what came to pass before it' (Lingis, 1998: xx), in ways that are, for many, the very stuff of daily existence. 


\section{References}

Anjaria, J. S., (2006) A View from Mumbai. Space and Culture 9 (1): 80-2.

Banks, N., Roy, M and Hulme, D (2011) Neglecting the urban poor in Bangladesh: research, policy and action in the context of climate change. Environment \& Urbanization. 23 (2) 487- 502.

Barnett C and Land D (2007) Geographies of generosity: beyond the moral turn Geoforum 38 1065-75

Bettini, G. (2014). Climate migration as an adaption strategy: de-securitizing climateinduced migration or making the unruly governable? Critical Studies on Security, 2(2), 180-195.

Clark, N (2010) 'Volatile Worlds, Vulnerable Bodies: Confronting Abrupt Climate Change', Theory, Culture \& Society, 27 (2-3): 31-53.

Clark, N (2011) Inbuman Nature: Sociable life on a dynamic planet. London: Sage.

Clark, N (2016) `Anthropocene Incitements: Toward a Politics and Ethics of Ex-orbitant Planetarity in Van Munster, R and Sylvest, R (eds) Assembling the Planet: The Politics of Globality Since 1945, London: Routledge, pp126-44.

Clark, N., Chhotray, V. and Few, R. (2013) 'Global Justice and Disasters', Geographical Journal. 179 (2): 105-113

Clark, T (2015) Ecocriticism on the Edge: The Anthropocene as a Threshold Concept. London: Bloomsbury.

Derrida, J. (1995) The Gift of Death. Chicago: University of Chicago Press.

Diprose, R. (2002) Corporeal Generosity: On giving with Nietzsche, Merleau-Ponty, and Levinas. Albany, NY: State University of New York Press. 
Flannery, T. (2005) The Weather Makers: the history and future impact of climate change. London: Allen Lane.

Gunaratnam, Y (2013) Death and the Migrant: Bodies, Borders and Care. London:

Bloomsbury.

Gunaratnam, Y and Clark, N (2012) Deep Race: Climate Change and Planetary Humanism, Darkmatter 9 (1) online at:

http://www.darkmatter101.org/site/2012/07/02/pre-race-post-race-climate-changeand-planetary-humanism/

Holderness and Turpin, E. (2016) How tweeting about floods became a civic duty in Jakarta. The Guardian. Online at: http://goo.gl/I1uOVt (accessed 22 April, 2016)

Jabeen, H., Johnson, C and Allen, A (2010) Built-in resilience: learning from grassroots coping strategies for climate variability, Environment \& Urbanization 22 (2): 415-431.

Jasanoff, S (2011) A new climate for society, Theory, Culture \& Society, 27(2-3): 233-253.

Lingis, A. (1998) 'Translator's introduction’ in E. Levinas, Otherwise Than Being Or Beyond Essence, London: Kluwer Academic Publishing.

Mosuela, C. and Matias, D. M. (2014). 'The role of a priori cross-border migration after extreme climate events: The case of the Philippines after typhoon Haiyan', COMCAD Arbeitspapiere Working Papers 126. Bielefeld: Universität Bielefeld.

Newell P (2005) Race, class and the global politics of environmental inequality, Global Environmental Politics 5 70-94

Roberts, J. T. and Parks, B. 2007. A Climate of Injustice. Cambridge, MA: MIT Press.

Roy, M., Hulme, D. and Jaha, F (2013) Contrasting adaptation responses by squatters and low income tenants in Khulna, Bangladesh, Environment \& Urbanization 25 (10): $157-167$.

Steffen W, Sanderson A, Tyson P et al (2004) Global Change and the Earth System: A Planet Under Pressure. Berlin: Springer-Verlag. 
Vaughan, G (2002) 'Mothering, Co-muni-cation, and the Gifts of Language' in E.

Wyschogrod, J-J. Goux and E. Boynton (eds) The Enigma of Gift and Sacrifice. New York: Fordham University Press

Valeri, K. A. (2014). `Storm of Violence, Surge of Struggle: Women in the Aftermath of Typhoon Haiyan (Yolanda)', Asian Journal of Women's Studies, 20 (1): 148-163.

van Wyck P (2010) Highway of the Atom. Montreal \& Kingston: McGill-Queens University Press.

York, C (2015) Muslims Helping With UK Flood Response But Britain First And EDL Nowhere To Be Seen. Huffingdon Post UK. Online at:

http://www.huffingtonpost.co.uk/2015/12/28/muslims-flooding-britain-first-englishdefence-league_n_8886142.html (accessed 22 April 2016). 
